INVESTIGACIÓN

http://doi.org/10.15198/seeci.2019.49.59-80

Recibido: 26/10/2018 --- Aceptado: 22/03/2019 --- Publicado: 15/07/2019

\title{
EL PERIODISMO COMO ARMA DE CAPTACIÓN TERRORISTA
}

\section{JOURNALISM AS A TERRORISM CAPTATION WEAPON}

Miguel Ángel Poveda Criado1. Universidad Europea de Madrid. España. Mapoveda1@yahoo.es

\section{RESUMEN}

El presente ensayo pretende explicar el uso que hace el Daesh del periodismo para captar adeptos. En primer lugar, se aborda el marco teórico para situar a la organización terrorista en el contexto actual; se indaga en su financiación para entender su poder; se investigan los medios de comunicación que tienen, a través de los cuales distribuyen su propaganda; se analiza el mensaje que transmite, al público al que se dirige y los métodos de captación que emplea; se estudia el uso que hace de Internet, en especial de las redes sociales, consiguiendo así gran alcance y repercusión; se analizan vídeos de gran calidad producidos por la organización a través de los cuales difunden propaganda y tratan de sembrar el terror; se aborda la radicalización violenta de aquellos que se unen a las filas del Daesh, así como sus motivaciones y los datos que revelan el número de combatientes extranjeros que se han trasladado a Siria e Irak para luchar con el grupo terrorista. Y finalmente, las conclusiones demuestran que la agrupación terrorista ha sabido sacar el máximo partido a las nuevas tecnologías de la información y la comunicación en una época en la que están sumamente desarrolladas, para hacer un llamamiento a todos aquellos que quieran unirse a su causa, crear su califato. Por tanto, los resultados que ha ido cosechando la organización yihadista son abrumadores, puesto que ha conseguido captar a individuos de todo el mundo para unirse a sus filas.

PALABRAS CLAVE: Daesh - terrorismo - yihadismo - medios de comunicación propaganda - internet - radicalización violenta - reclutamiento - captación.

\section{ABSTRACT}

This actual work pretends to explain how useful journalism for Daesh is to gain followers. In first place, it approaches the theoretical framework to position the terrorism organization in the actual context, it inquires in their financing to know about their authority. It researches which media they have, through those who share their blurb; it analyzes the message that transmits, to the spectators it refers to,

1 Miguel Ángel Poveda Criado: Doctor en Periodismo por la UCM, doctor en Paz y Seguridad Nacional por la UNED y doctor europeo en Ciencias Sociales y Políticas por la Universidad Técnica de Lisboa (UTL). Licenciado en Comunicación Audiovisual por la UCM. Máster en Seguridad y defensa por la UCM y el CESEDEN. 
recruitment methods they use; it studies the use they make of Internet, in particular the social media achieving repercussion and power; it analyses videos with a lot of quality produced from the organization through which spreads propaganda and try to terrorize; it addresses the violent radicalization who reunites to the queue of Daesh, like their motivations and the data that reveals the quantity of foreigners that moved away to Siria or Irak to fight with the terrorist group. And finally, conclusions show that the terrorism group, had know to take advantage to the new information and comunication technologies inside a date they are highly developed, appeal to anybody that wants to join their cause, create their caliphate. Therefore, the results that the yihadist organization have been reaping are overwhelming, they have achieved individuals all around the world to follow their rows.

KEY WORDS: Daesh - terrorism - yihadism - mass media - propaganda - Internet - violent radicalization - recruitment - captation.

\section{O JORNALISMO COMO ARMA DE CAPTAÇÃO TERRORISTA}

\section{RESUME}

O presente artigo pretende explicar o uso que dá ao jornalismo o grupo de terroristas Isis para captar adeptos. Em primeiro lugar, se aborda o marco teórico para situar essa organização terrorista no contexto atual; se indaga em seu financiamento para entender seu poder; se investigam os meios de comunicação que tem, através dos quais distribuem sua propaganda; se analisa a mensagem que transmitem, ao público que se dirigem e os métodos de captação que empregam; se estuda o uso que fazem da internet, em especial das redes sociais, conseguindo assim um alcance e repercussão; se analisam vídeos de grande qualidade produzidos pela organização através dos quais difundem propaganda e tratam de plantar 0 terror; se aborda a radicalização violenta daqueles que se unem a esta banda, assim como suas motivações e os dados que revelam o número de combatentes estrangeiros que se trasladaram a Síria e Iraque para lutar com o grupo terrorista. E finalmente, as conclusões demonstram que esta agrupação terrorista soube tirar o máximo partido das novas tecnologias da informação e da comunicação em uma época na qual estão superdesenvolvidas, para fazer um chamamento a todos aqueles que queiram unir-se a sua causa, criar seu califado. Portanto, os resultados que foram colhendo esta organização são assustadores, uma vez que conseguiram capturar a indivíduos de todo o mundo para unir-se a sua banda.

PALAVRAS CHAVE: Isis - terrorismo - jihadismo - meios de comunicação propaganda - internet - radicalização violenta - recrutamento - captação.

\section{Cómo citar el artículo:}

Poveda Criado, M. A. (2019). El periodismo como arma de captación terrorista [Journalism as a terrorism capitation weapon]. Revista de Comunicación de la SEECI, 49, 59-80. doi: http://doi.org/10.15198/seeci.2019.49.59-80

Recuperado de http://www.seeci.net/revista/index.php/seeci/article/view/559 


\section{INTRODUCCIÓN}

La relevancia de esta investigación reside en la gran repercusión que tiene el Daesh en el panorama actual, haciendo un uso magistral de las nuevas tecnologías de la información y la comunicación para darse a conocer a nivel mundial y, de este modo, expandirse y conseguir adeptos, al mismo tiempo que trata de sembrar el terror. La amenaza del terrorismo global que representa la organización gracias a la visibilidad que consigue a través de los medios de comunicación e Internet, destacando las redes sociales, suscita debates y genera inquietudes a nivel mundial sobre esta mutación del terrorismo tradicional. Son numerosos los teóricos que analizan este fenómeno y que lo consideran modelo paradigmático de la "guerra híbrida". Es, por tanto, imprescindible conocer su aparato propagandístico, ya que supone uno de los pilares fundamentales sobre los que se sustenta el Daesh.

\section{OBJETIVOS}

Los objetivos que se plantean con este estudio son los siguientes:

- Saber cómo se financia el Daesh para desarrollar su actividad.

- Descubrir qué medios de comunicación forman parte del aparato propagandístico del grupo terrorista.

- Conocer el alcance y repercusión que tiene su capacidad comunicativa.

- Indagar en la importancia del uso que hace la organización de las redes sociales y su efectividad.

- Estudiar el perfil de su público objetivo y de los radicalizados.

- Analizar sus producciones audiovisuales.

- Estudiar las causas de la radicalización y las formas de reclutamiento.

- Obtener datos cuantitativos de la efectividad de la captación.

\section{METODOLOGÍA}

En cuanto a la metodología que se sigue en el artículo, la información se obtiene principalmente de diversos autores especialistas en arabismo y terrorismo yihadista, los cuales aportan distintos puntos de vistas analizando este fenómeno. Algunos de los investigadores más destacados son:

- Luis de la Corte Ibáñez, director del área de Estudios Estratégicos e Inteligencia del Instituto de Ciencias Forenses y de la Seguridad ICFS-UAM, profesor titular del departamento de psicología social y metodología. Sus principales investigaciones tratan de temas de Seguridad y Defensa en particular, terrorismo y otras formas de violencia política y crimen organizado, estudios estratégicos, análisis de inteligencia y Psicología Social.

- Javier Lesaca, periodista especializado en arabismo e investigador visitante en la Facultad de Comunicación y Asuntos Públicos de la George Washington University, donde está investigando la estrategia de engagement audiovisual del Daesh.

- Fernando Reinares, investigador principal y director del Programa sobre Terrorismo Global del Real Instituto el Cano, y catedrático de Ciencia Política y Estudios de Seguridad en la Universidad de Georgetown en Washington. 
Además, fue presidente del grupo de Expertos en Radicalización Violenta de la Comisión Europea (2007-2009) y asesor para asuntos de política antiterrorista del ministro del Interior (2004 y 2006).

- Javier Jordán, profesor titular del Departamento de Ciencia Política y de la Administración en la Universidad de Granada y director del Máster en Estudios Estratégicos y Seguridad Internacional y de la revista Estudios en Seguridad Internacional (RESI). Además, es miembro del Observatorio Internacional de Estudios sobre Terrorismo del Colectivo de Víctimas del Terrorismo (COVITE) y del grupo de Estudios en Seguridad Internacional (GESI).

- Patrick Cockburn, de nacionalidad irlandesa, es uno de los corresponsales más prestigiosos de Oriente Próximo, primero para el Financial Times, y actualmente para The Independent (Cockburn, 2015).

- Loretta Napoleoni, de nacionalidad italiana, es economista, escritora, periodista y analista política. Es experta en terrorismo y en su financiación (Napoleoni, 2015).

Por otro lado, es necesario acudir a algunos organismos para obtener ciertos datos, como son:

- The Institute for the Study of War (ISW), es un centro de estudios con sede en Estados Unidos, que ofrece investigaciones y análisis sobre temas de defensa y relaciones exteriores.

- El Observatorio Internacional de Estudios sobre Terrorismo (OIET), es un organismo que promueve el desarrollo de proyectos de investigación enfocados a la prevención de la radicalización violenta y a la difusión de principios democráticos.

- El Instituto Español de Estudios estratégicos (IEEE), es un organismo del Ministerio de Defensa de España dependiente del Centro Superior de Estudios de la Defensa Nacional (CESEDEN) y del secretario general de Política de Defensa.

- Real Instituto el Cano es un think-tank de estudios internacionales y estratégicos que analiza el mundo desde una perspectiva española, europea y global.

- Soufan Group es una empresa que proporciona servicios de inteligencia y seguridad estratégica a los gobiernos y organizaciones multinacionales.

Además, en algunos casos ha sido necesario consultar algunos diarios para obtener información sobre los medios de comunicación que posee el Daesh, puesto que en la búsqueda documental existe escasa información al respecto, a excepción de la revista Dabiq.

En cuanto a la estructura que se sigue en el trabajo, es necesario comenzar por el marco teórico para conocer el significado de yihad, lo que representa el yihadismo global y cuáles han sido sus fases, el papel de Al Qaeda y cómo surgió el Daesh. Además, es importante saber cómo se financia el grupo para desarrollar su actividad y cómo ha conseguido su independencia económica. Por otro lado, se abordan los medios de comunicación que la organización tiene y utiliza para distribuir contenidos propagandísticos, así como el uso que hace de las redes sociales con el mismo 
objetivo. Y como resultado de estos procesos comunicativos del Daesh, se pretende conocer el impacto que tiene en su público, provocando la radicalización y el reclutamiento de individuos de todo el globo terráqueo, siendo un proceso que se consuma a gran velocidad.

\section{DISCUSIÓN}

\subsection{Medios de comunicación y propaganda}

Según Javier Lesaca, investigador del Observatorio Internacional de Estudios sobre Terrorismo, el Daesh "se ha convertido en uno de los fenómenos más importantes en el ámbito de la comunicación pública desde comienzos de siglo". Habla de que la organización terrorista ha generado un nuevo tipo de terrorismo que usa el marketing y la comunicación digital no solo para extender el terror a nivel global, sino también para transformar el terror en algo popular, deseable e imitable (Lesaca, 2015).

Gonzalo Caretti, experto en el conflicto de Oriente Medio, explica que el objetivo de la propaganda del Daesh es triple: "aterrorizar al adversario, reclutar adeptos y tratar de rescatar la utopía suní de la creación de un nuevo orden político que ponga fin a lo que consideran siglos de humillación". Para conseguirlo se vale de los recursos técnicos, del manejo de los flujos informativos, de las redes sociales y del conocimiento de los medios occidentales como canales para expandir de manera involuntaria sus mensajes. Además, la organización juega con dos cartas importantes, como son el control total de toda la información que entra y sale de las zonas que tiene bajo su dominio y la demanda de información sobre todo lo que acontece en Siria e Irak. El periodista añade, que desde que el Daesh fuera al-Qaeda en Irak ya había realizado inversiones importantes en los medios de comunicación por su interés en crear sus propios contenidos. De hecho, en 2009 la organización fundó su primera división de medios llamada Al Furqan. En la actualidad, el Daesh posee tres grandes divisiones desde las que difunde su propaganda y más de 30 productoras audiovisuales ${ }^{2}$.

\subsubsection{Televisión}

Según la agencia de noticias Sputnik, el Daesh tiene su propio canal de televisión vía satélite para difundir contenidos propagandísticos. Se llama Bein HD4, que se emite en Nilesat, una compañía egipcia, y cuenta con más de 500 mil espectadores, de acuerdo con el diario Mirror. Entre su programación se puede encontrar información militar relacionada con los ataques, conferencias sobre el islam, predicciones meteorológicas, etc. Por otro lado, el grupo terrorista se ha encargado de confiscar las antenas parabólicas de todas las viviendas que se encuentran en las zonas que tienen bajo su dominio. El Observatorio Sirio de Derechos Humanos también ha informado de que los terroristas dieron de plazo hasta el Ramadán para

\footnotetext{
${ }^{2}$ http://www.rtve.es/noticias/20160805/propaganda-del-daesh-arma-mas-eficaz-del-califatoterrorista/1381785.shtml
} 
que los comerciantes que venden estos aparatos dejen de hacerlo de manera definitiva. Además, los integrantes del grupo repartieron folletos entre la población para prohibir la utilización de las antenas. La intención es evitar que la población pueda acceder a contenidos que escapan de su control, bajo el pretexto de que dichos contenidos pueden contaminar y alejar a los espectadores de la "buena práctica" islámica, apoyándose para justificar esta medida en veinte motivos religiosos. Animan, además, a consumir los "medios islámicos" y los productos audiovisuales que produce y difunde el Daesh para mantenerse informados ${ }^{3}$.

\subsubsection{Radio}

El Daesh tiene una estación de radio en Mosul, llamada Al-Bayan, que es su estación principal, y cubre todas las operaciones militares en Siria e Irak. Las emisiones se dan en árabe, kurdo, francés, ruso e inglés, según el diario de Medio Oriente, Albawaba. Además, contaba con otra en Afganistán, denominada "La voz del Califato", la cual fue destruida en el mes de febrero de 2016 en un ataque estadounidense. La estación de radio funcionaba en Nangarhar y difundía mensajes propagandísticos para captar adeptos, sobre todo a los más jóvenes, y así provocar un levantamiento contra el gobierno afgano. El objetivo era ejercer presión psicológica sobre los habitantes. En cuanto a la lengua, inicialmente emitía en pastún ${ }^{4}$ y más recientemente había incluido el dari ${ }^{5}$ y el inglés ${ }^{6}$.

\subsubsection{Publicaciones}

La organización posee una importante revista oficial, llamada Dabiq, la cual ha sido creada como una herramienta más de captación. Se trata de una publicación de alta calidad, equiparable a otras del mercado de la talla de National Geographic. La revista es publicada por al Hayat (central de medios del Daesh), tiene periodicidad mensual y se distribuye a través de Internet. En cuanto a la maquetación es elegante, atrevida, da protagonismo a los grandes titulares y fotografías, siguiendo la línea de Time o The New Yorker. El lenguaje empleado es muy ornamentado y el discurso apocalíptico, deformando la realidad y amenazando a Occidente. El idioma que utiliza es el inglés, puesto que su público objetivo es el musulmán occidental, sobre todo el adolescente (Caretti, 2016). Su contenido es variado: información sobre su actividad, incitación al odio y a la violencia, reclutamiento, reproches a dirigentes occidentales, auto engrandecimiento, entrevistas de los líderes de la organización, etc. Además, tiene un semanario llamado Al Naba, que sigue la misma línea propagandística.

3 http://www.antena3.com/noticias/mundo/daesh-lanza-campana-prohibir-antenas-parabolicas-siriairak-porque-siembran-rumores 20160601574f45694beb28110c2a31f6.html

${ }^{4}$ De acuerdo con el DRAE: "lengua irania oriental que se habla en Afganistán y Pakistán".

${ }^{5}$ Lengua persa que se habla en Afganistán. El dari y el pastún son los dos idiomas oficiales de Afganistán.

6 https://www.abc.es/internacional/abci-dron-eeuu-destruye-califato-emisora-radio-estado-islamicoafganistan-201602021717 noticia.html 


\subsubsection{Agencias de noticias}

El Daesh cuenta con una agencia de noticias, llamada Amaq, la cual se ha convertido en una pieza muy importante en la estrategia propagandística de la organización. Felipe Sahagún, periodista especializado en política internacional, dice que esta agencia es la primera en informar de los atentados que perpetra el grupo terrorista y que, además, es la que mejor lo hace. "Recibe las exclusivas directamente del ISIS y, para quienes siguen de cerca el yihadismo violento, se ha convertido en lectura obligada cada vez que explota una bomba", agrega Rukmini Callimachi, periodista de asuntos internacionales del New York Times. También expone que Amaq le da voz al Daesh y que, aunque la agencia no sea, de manera oficial, parte del aparato propagandístico de la organización yihadista, actúa como si lo fuese.

Según Sahagún, los investigadores de SITE, uno de los principales organismos de seguimiento del Daesh, tuvieron constancia por primera vez de la existencia de Amaq en el año 2014 en la batalla de Kobani, pero no se supo de la verdadera vinculación que esta tenía con la agrupación yihadista hasta el atentado en San Bernardino, California. Apunta Rita Katz, jefa del equipo de seguimiento de la agrupación en SITE: "ISIS se considera un Estado y utiliza Amaq como su agencia estatal"7.

\subsubsection{Redes sociales}

Francisco Martínez, secretario de Estado de Seguridad del gobierno español, ha destacado en el "Simposium sobre Salafismo, Yihad y Análisis de Conducta" que tuvo lugar en el mes de marzo de 2016, el manejo novedoso que hace el Daesh de las redes sociales e Internet, muy parecido a la publicidad comercial ${ }^{8}$. Son numerosas las redes sociales que usa la organización para captar a nuevos integrantes, extender el terror y despreciar a los occidentales, convirtiendo así estas plataformas en armas de guerra. Los yihadistas son muy activos en estas redes, publicando contenidos y creando nuevas cuentas, como, por ejemplo, en Twitter, ya que en cuanto se detecta que los terroristas se encuentran tras ellas, son eliminadas. Todo lo que produce el Daesh se distribuye a través de las redes sociales de una manera muy profesional. Se trata de la forma más eficaz y rápida que tiene de difundir su propaganda a todos los rincones del mundo. Su efectividad es tal, que, tras la toma de Mosul, sus cuentas de Twitter enviaron más de 40.000 tweets en 24 horas. Algunas de las redes sociales que usan son: Instagram, Facebook, Youtube, Twitter, Whatsapp, Telegram, Skype, Diaspora, Kik, etc.

\subsubsection{Productoras}

Lesaca menciona que el Daesh ha creado una red de 29 productoras audiovisuales, de las cuales tres se encargan de hacer producciones dirigidas a una audiencia global (AL Furqan, Al Ittissam y Al Hayat), y las otras 26 crean productos

\footnotetext{
7 http://www.elmundo.es/television/2016/01/18/569a809b22601dca238b4667.html

8 http://www.interior.gob.es/prensa/noticias/-/asset publisher/GHU8Ap6ztgsg/content/id/5732932
} 
segmentados para cada región que controla el grupo terrorista en Siria, Irak, Egipto, Libia, Yemen, el oeste de África y Afganistán. El número se ha ido ampliando, como es el caso de la productora del Cáucaso en Rusia y de dos más en Yemen (Lesaca, 2015). Por su parte, Francisco Martínez asegura que en la actualidad la organización cuenta ya con "una red de 36 productoras audiovisuales que producen vídeos, en los que en un $16 \%$ se muestran ejecuciones donde aparecen más de 1.500 personas asesinadas, musulmanes en su mayoría".

\subsubsection{Aplicaciones}

El grupo terrorista ha desarrollado varias aplicaciones para Android, como "Fajr al- Basha'ir" (Amanecer de Buenas noticias/The Down of Glad Tidings), que estuvo disponible a través de la tienda de Google Play desde el año 2014 hasta su retirada. Esta aplicación móvil en lengua árabe difundía las noticias más recientes de Siria, Irak y el mundo islámico. Por otro lado, la agencia Amaq también cuenta con su propia aplicación para difundir noticias de primera mano concernientes a la organización yihadista durante las 24 horas del día9 .

\subsubsection{Otras plataformas}

El Daesh también hace uso de otras plataformas como JustPaste para pegar textos, SoundCloud para audios, VideoPress para alojar vídeos en blogs compatibles, Instagram como escaparate de imágenes, Whatsapp para chatear, Ask.fm que es una red muy sencilla que une a internautas mediante preguntas y respuestas, etc.

Por otro lado, el grupo crea otros productos que utiliza para hacer propaganda, como sus propios videojuegos, pósters, CD's, DVD's, merchandising, etc, de acuerdo a James Comey, director del FBI.

\subsection{Alcance y repercusión}

\subsubsection{Mensaje}

El mensaje que el Daesh difunde a los jóvenes musulmanes radicalizados o vulnerables a ello, en Estados de mayoría musulmana o entre musulmanes que viven en Occidente, es conformar una nueva sociedad yihadista. Se refieren a un califato limitado territorialmente, pero con expectativas de expansión, con un orden social y político para comenzar una nueva vida, con una nueva identidad colectiva que les represente a sí mismos y que sea reconocida por todos. Envían un mensaje atractivo, cargado de promesas, dando un halo de esperanza a aquellos colectivos que buscan cambiar de vida y formar parte de algo grande (Reinares, 2015).

Según explica Harleen Gambhir, analista de contraterrorismo del Institute for the Study of War, la capacidad comunicativa de la organización es sumamente eficaz,

\footnotetext{
${ }^{9}$ https://www.albawaba.com/slideshow/radio-broadcasts-mobile-apps-here\%E2\%80\%99s-howdaesh\%E2\%80\%99s-propaganda-machine-works-773434
} 
gracias a su habilidoso uso de las tecnologías y al empleo de los medios de comunicación. Todo el contenido que publican a través de diferentes medios hace hincapié en su principal reivindicación, la de crear un califato, al que todos los musulmanes creyentes están obligados a defender. Además, el Daesh cuenta con una base central desde donde controla los mensajes y la propaganda que lanza al mundo, y donde establece un orden de prioridades en las informaciones y las campañas mediáticas que va a llevar a cabo bajo la supervisión de al-Bagdadí y su Consejo. Estos mensajes se distribuyen luego a través de diferentes canales, incluidos los medios de comunicación oficiales del Daesh, oficinas de información provincial, colectivos de medios no oficiales e Internet. Al existir un receptor heterogéneo, el mensaje tiene que adaptarse según el público al que pretenden persuadir. Por tanto, la comunicación no será la misma para los sirios e iraquíes, que para Occidente. De esta forma, ganan credibilidad frente a las diferentes poblaciones, incluso repitiendo siempre su mensaje central. A pesar de que la organización es líder en el uso de los medios de comunicación para sembrar el terror y ganar adeptos, también otros grupos yihadistas siguen los mismos pasos. Así que tendrán que seguir reinventándose para no perder esa ventaja (Gambhir, 2016).

Según explica Jordán, el Daesh ha sabido muy bien cómo transmitir sus éxitos a través de una extraordinaria utilización de la propaganda a través de Internet, consiguiendo gran alcance y repercusión gracias a las redes sociales. Ha combinado un mensaje de victoria con uno de extrema brutalidad contra sus enemigos, y, además, con una forma de culto a la muerte. "Aunque a primera vista pueda parecer irracional, esta exaltación de la violencia y su magnificación a través de la propaganda han desempeñado un rol paramilitar de primer orden, minando la moral de sus adversarios" agrega el analista. De este modo, el grupo terrorista ha convertido su modus operandi en ejemplo paradigmático de lo que se ha dado en llamar guerra híbrida ${ }^{10}$ (Jordán, 2015, p. 126).

El Daesh trata de transmitir que quiere ser para los musulmanes suníes lo que Israel significa para los judíos, un Estado en un territorio que un día les perteneció y que tienen que recuperar; un gran Estado religioso que siempre les protegerá (Napoleoni, 2015, p. 18).

En la revista Dabiq pueden verse ejemplos de su llamada a todos los musulmanes del mundo: "el resurgimiento del califato proporciona a cada individuo musulmán una entidad concreta y tangible para satisfacer su natural deseo de pertenecer a algo grande"señala Reinares (Reinares, 2015).

\footnotetext{
${ }^{10}$ No existe un consenso ni en cuanto a la denominación ni a la definición de este término. Pedro Sánchez Herráez, citando a Hoffman, se refiere a amenaza híbrida como: "cualquier adversario que de manera simultánea y adaptativa emplea una mezcla de armas convencionales, tácticas irregulares, terrorismo y comportamiento criminal en el espacio de batalla para alcanzar sus objetivos políticos". Otros teóricos denominan esta clase de coyuntura como "guerra compuesta" o "combinada", mientras que algunos como Albero definen la guerra híbrida "como aquella en la que al menos uno de los adversarios recurre a una combinación de operaciones convencionales y guerra irregular, mezclada esta última con acciones terroristas y conexiones con el crimen organizado"(Alonso, 2015, p. 65).
} 
La propaganda que lleva la organización armada, también se centra en crear y difundir el mito de al Bagdadí y el nuevo califato, puesto que en el islam existe la incógnita del retorno del Profeta. De este modo, atemoriza a Occidente con crueles asesinatos y a sus adeptos musulmanes les hace creer que el Profeta ha vuelto personificado en al Bagdadí (Napoleoni, 2015, pp. 20-21).

Napoleoni puntualiza que el Daesh muestra su capacidad de actuación mediante la violencia, la sharía y las redes sociales propagandísticas, y a través de unas medidas sociales populares que favorecerían la situación de los suníes atrapados en el territorio del califato (Napoleoni, 2015, p. 21).

\subsubsection{Público}

Según unas declaraciones de Shiraz Maher, exmiembro del International Centre for the Study of Radicalization del Kings College de Londres, el líder del Daesh admite a cualquier individuo que desee unirse a sus filas, a diferencia de otras organizaciones que tienen reticencias para incorporar a cualquier combatiente por miedo a posibles filtraciones. Aunque hay que destacar que su principal objetivo son los jóvenes (Napoleoni, 2015, p. 35).

La agrupación yihadista intenta llamar la atención de los jóvenes musulmanes carentes de futuro, que viven en países azotados por la corrupción, la desigualdad o la injusticia de los gobiernos islámicos actuales. Como fue la cruel dictadura de Bashar al Assad, el rechazo de Maliki para integrar a los suníes en la vida política de Irak y su continua persecución, el intento frustrado para recuperar la infraestructura socioeconómica devastada por la guerra y la preocupante tasa de desempleo. Estos hechos favorecen que estos colectivos sean más vulnerables y quieran salir de la situación en la que se encuentran (Napoleoni, 2015, p. 19). Lo mismo ocurre con jóvenes musulmanes que viven en países europeos o norteamericanos, que se ven sin futuro, que no logran integrarse en la sociedad occidental, y en la cual ven cada vez menos oportunidades para su generación. La organización se aprovecha de las frustraciones de los musulmanes de todo el mundo, haciéndoles así, un llamamiento para que se unan a su lucha y ayuden a construir su califato (Napoleoni, 2015, p. 19).

Según David Garriga Guitart, experto en terrorismo yihadista, existe dificultad a la hora de clasificar a estos terroristas, debido a la variedad de perfiles. Sin embargo, se han observado algunas peculiaridades que se repiten en varios de los integrantes, "como la radicalización en chicos y chicas de segunda y tercera generación, musulmanes no practicantes, nivel de estudios básico, usuarios de las redes sociales $e$ incremento de los conversos" explica Garriga. Por otro lado, un estudio reciente con distintos países de Europa en el que se ha analizado a radicalizados y reclutadores investigados por delitos de terrorismo, se ha detectado que existen ciertas variables que van modificándose con el paso del tiempo, tales como "la media de edad que disminuye, la captación ya no solo es por redes sociales sino que aparecen los videojuegos, la mayoría de chicos no viajan a Siria o Irak como última fase de radicalización y aumentan los porcentajes de antecedentes de delincuencia común"agrega Garriga (Garriga, 2016). 
De la Corte, haciendo referencia a Reinares y García Calvo, menciona que, aunque la cifra de mujeres que se unen a las filas del Daesh va en aumento, la gran mayoría son hombres, que no suelen sobrepasar los 35 o 40 años. En Occidente la mayoría de los individuos que se unen a las filas de la organización suelen tener más de 25 años, nacidos y criados allí, pudiendo tener también ascendencia de países musulmanes. Asimismo, existen casos de individuos radicalizados en Europa que son conversos o inmigrantes de primera generación. Según Sageman y en palabras del investigador de la Corte, la mayoría de los sujetos apenas tienen una instrucción religiosa y no siguen los preceptos del islam, pero también hay individuos que eran muy religiosos antes de adquirir una orientación extremista. Respecto al nivel educativo, socioeconómico y la ocupación, existen desde personas con estudios universitarios a otras con baja formación académica; desde casos con escasos recursos a individuos de clase media; desde sujetos desempleados hasta algunos con trabajos estables y con sueldos altos. En cuanto al estado civil, lo normal es la soltería, pero también se han dado bastantes casos en los que se contrae matrimonio, se adquiere descendencia y después se radicalizan. Muchos yihadistas antes de su transformación habían cometido delitos dice de la Corte, citando a Ranstorp; otros procedían de familias desestructuradas o habían sufrido algún tipo de trastorno mental, aunque estos dos últimos factores no han sucedido con frecuencia. En definitiva, no se puede hablar de un solo perfil, sino que existe una variedad, añade de la Corte haciendo referencia a Kimhi y Even y a Nesser (de la Corte, 2015).

\subsubsection{Captación}

Napoleoni explica que cuando al Bagdadi fue elegido califa, desarrolló con gran destreza una campaña de propaganda con la que consiguió captar a muchos combatientes del extranjero (Napoleoni, 2015, p. 35). El Daesh hace uso de la "propaganda del miedo", ya que conoce el poder que tiene sembrar este sentimiento, mucho mayor que los sermones religiosos que predicaba al-Qaeda. El Daesh sabe bien que la violencia bárbara incita expectación y se convierte en noticia, sobre todo en un mundo en el que existe tal abundancia de información, en el que el flujo de noticias es constante durante las veinticuatro horas del día y en el que se demanda gran número de imágenes (Napoleoni, 2015, pp. 19-20).

Por su parte, de la Corte, basándose en Sageman,y en referencia al proceso de captación, aporta que los primeros contactos con personas radicalizadas, oradores radicales o integrantes de organizaciones terroristas no tienen por qué ser buscados, sino que también pueden darse de manera imprevista y fortuita. Además, el analista añade, apoyándose en Bakker, que los escenarios más típicos para entablar esos contactos suelen ser principalmente urbanos, normalmente barrios que aglutinan un número importante de integrantes pertenecientes a alguna diáspora. Estos espacios son casi siempre lugares de culto islámico, principalmente mezquitas. Pero también pueden ser lugares de ocio donde se practican costumbres musulmanas (como teterías o carnicerías halal) o espacios que suelen frecuentar musulmanes (como locutorios o cibercafés). Otros escenarios pueden ser formativos (universidades) o laborales (sobre todo pequeños comercios de musulmanes). Y las prisiones, donde también se han producido casos de radicalización. Algunas de las redes de captación

Revista de Comunicación de la SEECI. 15 julio, 2019 / 15 noviembre, 2019, no 49, 59-80 
no se desarrollan en un único espacio físico, lo cual se evidencia en los casos que derivan de relaciones de amistad y parentesco y a través de la interacción en Internet. Otras redes relevantes son las compuestas por seguidores y simpatizantes de movimientos y organizaciones islamistas y, por supuesto, las redes de captación y reclutamiento de agrupaciones yihadistas (de la Corte, 2015). Sin embargo, según los resultados de una investigación llevada a cabo por Scott Atran, experto en terrorismo de la Universidad de Oxford ${ }^{11}$, el $95 \%$ de los radicalizados extranjeros que deciden afiliarse al Daesh son captados por amigos y familiares. A su vez, de ese porcentaje, el $75 \%$ está influenciado por amigos y el $20 \%$ restante por familiares. Asegura además que, excepcionalmente, el reclutamiento tiene lugar en mezquitas, discrepando así con de la Corte y, por consiguiente, con Bakker ${ }^{12}$.

\subsection{Internet, el principal canal de distribución de la propaganda yihadista}

De la Corte expone que tanto los grupos yihadistas como sus seguidores explotan al máximo Internet y todas sus utilidades, como redes sociales, sitios web, foros, chats, blogs, mensajería electrónica, publicaciones multimedia, comunidades virtuales, etc. (Denotando la necesidad global de una educación mediática eficaz, como la defendida por Marta-Lazo, Grandío Pérez y Gabelas Barroso, 2013). De esta manera, Internet representa desde hace años el principal canal de distribución de la propaganda yihadista. La Red proporciona facilidades para entablar vínculos entre aquellos que son vulnerables a la radicalización con otros que están en vías o ya se han convertido y, de este modo, culminar con su conversión extremista. Además, el hecho de poder conectar a personas desde cualquier parte del mundo incide en la creencia de formar parte de un movimiento transnacional como pregona la propaganda yihadista. Por otro lado, Internet también ha favorecido las posibilidades de colaboración entre las organizaciones terroristas y los radicalizados, ya que a estos últimos les sirve para contactar y captar la atención de los primeros, y a los grupos terroristas, a su vez, para reclutar nuevos integrantes (de la Corte, 2015).

Algunos expertos auguran que se va a experimentar un aumento en el número de radicalizados online, llegando a las etapas finales sin necesidad de establecer un contacto físico con los individuos extremistas. Por el momento, los casos que se han dado han sido excepcionales, pero ello no significa que no vaya a suceder en un futuro en el que los mensajes y vínculos sociales en la Red seguirán proliferando, como viene ocurriendo desde hace más de diez años (de la Corte, 2015).

Por otro lado, explica Napoleoni, la organización terrorista hace uso de las redes sociales para difundir esmerados vídeos de sus macabras actuaciones $y$, de este modo, sembrar el pánico. A través de esta plataforma, es realmente fácil difundir contenidos en diversos formatos $y$, además, gracias a su inmediatez, puede llegar a multitud de personas en un intervalo de tiempo muy breve. También señala la

${ }^{11}$ Encuentro sobre combatientes terroristas extranjeros, llevado a cabo por el Comité de Lucha contra el Terrorismo del Consejo de Seguridad de la ONU.

12 http://www.infobae.com/2015/11/26/1772404-el-95-los-yihadistas-extranjeros-isis-son-reclutadosamigos-y-familiares/ 
periodista que debido al uso masivo y altamente cualificado que hace el Daesh de las redes sociales, ha suscitado falsos mitos para ganar seguidores, sumar combatientes y conseguir fondos dentro del mundo musulmán (Napoleoni, 2015, p. 20).

En palabras de David Garriga, actualmente existe un mayor número de personas que se radicalizan que hace unos años, porque con el uso de las redes sociales hay un mayor alcance. Asimismo, la exposición de propaganda terrorista es continua e intensiva a través de esta vía (Garriga, 2016). Este uso de las Redes ha influido a la hora de hacer llegar al entorno digital el concepto de la responsabilidad social de los Media aludido por Viñarás Abad (2010).

De acuerdo con datos proporcionados por Brookings Institution que se desprenden de una investigación llevada a cabo por Jonathan Morgan y J. M. Berger, de septiembre a diciembre de 2014, existían 46.000 cuentas en Twitter que controlaban seguidores del Daesh, y a través de las cuales sus mensajes llegan de manera inmediata a los dispositivos electrónicos de su audiencia. Uno de cada cinco seguidores elige el inglés como lengua principal en Twitter y tres cuartas partes prefiere el árabe. Gran parte del éxito de la organización en la red social se debe a la hiperactividad de un grupo relativamente pequeño de usuarios, que tiene entre $500 \mathrm{y}$ 2.000 cuentas. Muchas cuentas detectadas han sido suspendidas por Twitter, pero ello no les detiene para seguir creando nuevos perfiles y seguir con su actividad (Morgan y Berger, 2015).

Lister, siguiendo a Lorenzo Francheschi-Bicchierai, añade que a través de una red de cuentas a nivel provincial y de varios departamentos centrales de medios de comunicación, el Daesh superaba de manera significativa a cualquier otro grupo de militantes en Twitter hasta el mes de agosto de 2014, cuando se eliminó la totalidad de su estructura en esta red social, probablemente bajo petición del gobierno de los Estados Unidos (Lister, 2014, p. 24).

Los contenidos que difunde la organización terrorista consiguen importantes audiencias. Como, por ejemplo, el vídeo titulado "Salil al-Swarim" de una hora de duración, difundido por la productora Al-Furqan en el mes de marzo de 2014, el cual fue visto por 56,998 cuentas diferentes en Yotube en un intervalo de 24 horas. Dos meses después de su fecha de lanzamiento, el vídeo fue tuiteado 32,313 veces en un período de 60 horas, generando 807.25 tweets por hora. Estos datos demuestran el gran alcance y repercusión que tiene la actividad de los terroristas a través de Internet (Lister, 2014, p. 24).

\subsubsection{Vídeos propagandísticos}

Según explica Patrick Cockburn, la intención del Daesh es instaurar el terror, expandiendo a través de Internet imágenes macabras de los crímenes que cometen, como, por ejemplo, unos vídeos producidos, de gran dureza, en los que sus combatientes ejecutaban a soldados chítas y conductores de camiones con la intención de someter y desmoralizar a los soldados chítas en el momento de tomar Mosul y Tikrit (Cockburn, 2015, p. 15).

Crean multitud de productos audiovisuales de gran calidad con castigos, torturas extremas y asesinatos, utilizando técnicas muy sofisticadas, a la altura de las 
producciones hollywoodienses. Saben muy bien cómo explotar las nuevas tecnologías al servicio del terror y no se les escapa nada, hasta el punto de que adaptan los vídeos para que puedan ser visualizados desde teléfonos móviles (Napoleoni, 2015, p. 20).

La organización es conocedora de que el contenido que difunde despierta el morbo de la sociedad voyerista y virtual de la que formamos parte. De este modo, sabe cómo sacar provecho del sadismo que ofrece con una apariencia atractiva y convertirlo en espectáculo (Napoleoni, 2015, p. 20).

Según Javier Lesaca, desde que el Daesh comenzase en 2014 con su estrategia audiovisual, difunde una media mensual de 41 campañas propagandísticas, cifra que ha ido en incremento. Desde el 1 de enero de 2014 hasta el 24 de enero de 2016, los terroristas del Daesh han creado 1.060 vídeos, difundidos entre 46.000 y 75.000 cuentas de Twitter, añade Lesaca. Además, destaca la segmentación de audiencias y temáticas presentes en su campaña comunicativa, haciendo gala de su pasmosa sofisticación. En cuanto a la segmentación de audiencias, las producciones del Daesh son elaboradas tanto por su productora central Al Hayat, como por sus delegaciones territoriales en zonas sobre las que ejercen algún tipo de dominio con el objetivo de crear mensajes específicos para cada target. En cuanto a la diversificación temática, el investigador toma como ejemplo el mes de septiembre de 2015 , en el que de los 84 vídeos producidos y difundidos, el $25 \%$ mostraban batallas en las que los combatientes del Daesh se enfrentan a los ejércitos iraquíes y sirios; el $18 \%$ hacían gala de una vida fantástica en los territorios dominados por la organización; el $14 \%$ era relacionado con la gestión gubernamental y administrativa que lleva a cabo el Daesh en las zonas que están bajo su control; el $25 \%$ eran entrevistas a muyahidines de todo el mundo, incitando a otros musulmanes a formar parte de la Yihad terrorista; el 13\% restante exhibía alguna ejecución. Lesaca agrega que "el 22\% de los vídeos difundidos contenían algún tipo de imagen audiovisual inspirada en productos culturales populares de la cultura occidental, como videojuegos, videoclips musicales o películas y series". Se trata de una estrategia que la organización usa constantemente desde que comenzó con sus campañas con la pretensión de adaptarse a los gustos de los más jóvenes y, de esta manera, captar su atención. Por su parte, Gonzalo Caretti distingue hasta seis formatos con diferentes objetivos: las arengas y discursos religiosos, los vídeos nashid (cánticos con imágenes $)^{13}$, las ejecuciones ${ }^{14}$, falsos documentales y falsos reportajes informativos, que imitan con gran maestría los reportajes de la BBC o la CNN para crear confusión en la audiencia. Entre los trabajos más destacados se encuentran los realizados por el periodista norteamericano, John Cantlie, que fue secuestrado por el grupo terrorista. Laura Díaz, realizadora de TVE, tras analizar uno de los vídeos, comenta que usan una técnica muy publicitaria, ya que emplean un montaje muy rápido, en el que hay un bombardeo de imágenes que no permite pensar. Caretti continúa diciendo que los vídeos de la organización terrorista tienen unas características comunes: "un estilo visual sofisticado y efectista, inspirado en

\footnotetext{
${ }^{13}$ Caretti: "tienen como objetivo motivar a los simpatizantes, apelando a las emociones, y crea una falsa mitología de especial impacto entre jóvenes y adolescentes".

${ }^{14}$ la intención es atemorizar a la población occidental o mostrar su poder.
} 
películas o videojuegos, un mensaje apocalíptico y distorsionado sobre las interpretaciones del islam y unas mismas estrategias de distribución" (Caretti, 2016). Además, el grupo crea los vídeos en diferentes idiomas según a la audiencia que quiera dirigirse, como en inglés, ruso, francés o alemán. Por tanto, según Lesaca, la estrategia comunicativa del Daesh es un factor importante, casi tanto como el militar o su amenaza terrorista (Lesaca, 2015).

\subsection{Radicalización violenta}

De la Corte explica que la radicalización hace referencia al "proceso de cambio a través del cual puede avanzarse desde posiciones políticas y/o religiosas moderadas hacia radicales o extremas". Sin embargo, como los radicalismos ideológicos no tienen por qué ser todos violentos, algunos autores prefieren usar la expresión "radicalización violenta" para hacer alusión de manera más precisa a los casos en los que el cambio de ideología conlleve el uso de la fuerza, como es el caso actual del terrorismo yihadista (de la Corte, 2015).

Siguiendo a Wiktorowicz, de la Corte habla de que la radicalización se produce de manera gradual a través de varias etapas. Es necesario que exista una apertura mental para recibir y considerar nuevas formas de dar sentido a la propia existencia y al mundo. De esta manera, surge una primera fase de sensibilización, en la que los individuos comienzan a habituarse con el discurso y la visión del mundo yihadista. Después seguirán una o más fases en las que interioricen esas ideas y preceptos. El analista continúa diciendo:

En concreto, la radicalización conduce a la consolidación de una perspectiva fundada en la oposición moral entre "creyentes" y "no creyentes", generalmente acompañada del afianzamiento de una actitud "piadosa" y hostil que oriente al cumplimiento escrupuloso de los ritos islámicos y conceda legitimidad a la violencia presuntamente interpretable en términos de yihad: esfuerzo para seguir la senda y los deseos de Alá, defender al Islam de todos sus enemigos y preservar su pureza (de la Corte, 2015).

El proceso de radicalización también puede interrumpirse y no llegar a consumarse. De tal manera, que existen muchas más personas que se inician que las que completan todas las fases. En cuanto a la velocidad en la que se produce la radicalización depende del caso, aunque últimamente hay evidencias de que se ha experimentado cierta celeridad en dicho proceso (de la Corte, 2015).

De la Corte, apoyándose en Toboso, comenta que, en las primeras fases de radicalización de un individuo, se ha comprobado que siempre existe una relación con una o varias personas que ya tengan algún tipo de conexión o que pertenezcan a algún grupo terrorista. $Y$ a medida que se desarrolla el proceso, los sujetos se van distanciando de sus amistades anteriores y de sus grupos de referencia para estrechar lazos con aquellos ya radicalizados o en camino de estarlo. Una situación muy favorable para esto es aquella en la que los inmigrantes de países musulmanes llegan a otro país de acogida solos, sin familiares y sin ningún conocido (de la Corte, 2015). 
Dentro de los radicalizados existe una figura que hay que destacar, la conocida como "lobo solitario". Se trata de individuos que sufren una conversión extremista y que actúan por cuenta propia. Según el inspector de Policía, José María Benito, el perfil de estos individuos suele corresponder con un varón, musulmán o converso, que es autodidacta, activo en las redes sociales, no suele tener ni estudios ni trabajo y normalmente procede de barrios deprimidos. En los últimos tiempos han sido múltiples los casos de "lobos solitarios" que han perpetrado atentados y agresiones contra objetivos occidentales y musulmanes que no promulgan con el ideario del Daesh.

\subsection{Motivación}

De la Corte apunta que la radicalización no se produce por una sola motivación, sino por una mezcla de carencias, emociones, sentimientos y vivencias personales. Además, un individuo no puede radicalizarse si no tiene interés en ello, si no se ha movido por esos ambientes o si no se ha relacionado con sujetos o grupos radicalizados. De esta manera, la necesidad de pertenencia y reconocimiento social puede representar un estímulo para formar parte de grupos radicalizados, al igual que llevar a cabo ciertas conductas en busca de reconocimiento o admiración por parte de los líderes y compañeros del grupo. Y al mismo tiempo, la necesidad de significación puede motivar a hacer una nueva interpretación del mundo y de otorgar valor y sentido a la propia existencia. Otros alicientes que pueden empujar a la radicalización violenta puede ser la búsqueda de nuevas sensaciones, de aventuras, el afán de notoriedad, etc. Concluye este autor con lo siguiente:

Entre las vivencias y circunstancias personales que pueden activar las anteriores necesidades, motivos, deseos y sentimientos se incluyen experiencias de marginación o exclusión social; episodios (puntuales o reiterados) de discriminación interpersonal o intergrupal; maltrato o abuso por causa de la propia identidad nacional, étnica o religiosa; vivencias traumáticas de origen sociopolítico (represión y persecución, conflictos armados); y crisis familiares (pérdida de parientes) o personales (caída en la delincuencia, desengaños sentimentales) (de la Corte, 2015).

Según Napoleoni, uno de los hechos que ha hecho subir la popularidad del Daesh en el extranjero, especialmente entre los jóvenes musulmanes de Occidente, son las pocas trabas existentes para unirse a sus filas, lo cual va unido a su avanzado perfil comunicativo (Napoleoni, 2015, p. 35).

Reinares afirma que los triunfos del Daesh y su poder son un gran aliciente para las motivaciones individuales en la participación de actividades yihadistas, las cuales se interioriorizan mediante la radicalización. Por otro lado, la organización terrorista hace uso del factor psicológico para alimentar constantemente el odio hacia los que considera apóstatas, y también trata de remover sentimientos de humillación y frustración de grandes fracciones de poblaciones musulmanas afectadas por las injusticias (Reinares, 2015). 
Por su parte, de la Corte añade que existen diferentes factores que pueden determinar la radicalización yihadista:

El enfoque más reiterado ve en las expresiones violentas del extremismo islamista sunní el síntoma de alguna clase de disfunciones, conflictos o agravios sociales. Al confrontar a los futuros sujetos radicalizados con situaciones, vivencias o sucesos indeseables e indignantes (frustrantes, humillantes, crueles, etc.), esas disfunciones, conflictos o agravios pueden crear afinidades con los argumentos y relatos maniqueos y agresivos del salafismo yihadista (de la Corte, 2015).

El analista amplía la información enumerando algunas de las causas que influyen en la radicalización tanto en territorios musulmanes como occidentales: "regímenes políticos represivos y corruptos, la pobreza, divisiones $y$ tensiones sectarias, conflictos armados, condiciones de desigualdad $y$ discriminación generalizada padecidas por los miembros de las diásporas musulmanas establecidas en países no musulmanes, etc". (de la Corte, 2015).

Por otro lado, también existen otra serie de hechos puntuales que pueden ser malinterpretados por los musulmanes, promoviendo así sentimientos de odio en contra de Occidente (la definición misma de lo que para las RRPP en occidente es una crisis de malevolencia o, adecuadamente, terrorismo. García Ponce y SmolakLozano, 2013), según de la Corte "el inicio de una guerra entre países occidentales e islámicos, represión de partidos o asociaciones islamistas, prohibición del velo, publicación de opiniones y obras críticas con el islam, etc.". En un contexto en que la población tiene un acceso democratizado al conocimiento, pero no mecanismos normalizados para gestionar, interpretar y cribar esos datos, tal como sugieren Alonso Mosquera, Gonzálvez Vallés y Muñóz de Luna (2016). Además, hay que tener en cuenta dos sucesos que han contribuido de manera asombrosa al incremento en el número de radicalizados durante estos últimos años, como son las movilizaciones de protesta que acontecieron a finales de 2010 en varios países musulmanes, sobre todo en los que las revueltas han derivado en una fuerte represión o en guerras internas y el surgimiento del Daesh en junio de 2014 (de la Corte, 2015).

Según Cockburn, muchos jóvenes iraquíes se unen al Daesh por odio hacia su Gobierno, ya que no hace nada para impedir que la organización terrorista asesine a la población suní (Cockburn, 2015, p. 17). Una situación similar es la de Siria, en la que según Karen Koenig Abu-Zaid, miembro de la Comisión de Investigación de Naciones Unidas en Siria, afirma que cada vez son más numerosos los rebeldes sirios que están desertando para unirse al Daesh: "Ven que son mejores, que estos tipos son fuertes, que están ganando batallas, que están llevando el dinero, que pueden entrenarlos"(Cockburn, 2015, p. 18).

Un aspecto muy motivador son los éxitos militares que han cosechado en unos territorios cuya población está cansada de décadas de gobiernos déspotas, apoyados 
por Occidente; de la corrupción de la $\operatorname{OLP}^{15}$ y Hamás ${ }^{16}$; de las sanciones, luchas sectarias y guerras que nunca terminan (Napoleoni, 2015, p. 37). Según unas declaraciones de Richard Barrett, exjefe de contraterrorismo del servicio de inteligencia británico, para la agencia France-Presse, al Bagdadi ha llevado a cabo una campaña sorprendente: "ha tomado ciudades, ha movilizado un número extraordinario de gente, sus asesinatos en Irak y Siria son implacables... Cualquiera que desee combatir se unirá a Al Bagdadi"(Napoleoni, 2015, p. 37).

En Occidente, la llamada del Daesh tiene mayor efecto en Estados cuya población musulmana esta principalmente conformada por descendientes de inmigrantes originarios de naciones islámicas, que son las denominadas segundas e incluso terceras generaciones. Por tanto, son los jóvenes los más vulnerables, los cuales, en un momento de debilidad en sus vidas, sufren una crisis de identidad, para la cual el Daesh les propone una salida (Reinares, 2015).

De la Corte afirma, que otra de las motivaciones es la económica, puesto que el hecho de pertenecer a estos grupos extremistas sirve para satisfacer las necesidades básicas de los radicalizados o para obtener unos ingresos, en los casos en los que estos individuos carecían de empleo o sustento económico, situaciones que pueden ser consecuencia de un proceso migratorio (de la Corte, 2015).

\subsection{Reclutamiento}

Las campañas propagandísticas que realiza el Daesh a través de diferentes medios están siendo fructíferas, ya que según datos que se desprenden de investigaciones realizadas por Soufan Group, se calcula que alrededor de 31.000 personas de más de 100 países diferentes han viajado a Siria e Irak para unirse al Daesh y a otros grupos yihadistas. Tal ha sido el auge, que, en el primer estudio realizado por este organismo, fechado en el mes de junio de 2014, los combatientes extranjeros eran 12.000 procedentes de 81 países. La cifra se ha duplicado a pesar de los esfuerzos de la comunidad internacional por evitarlo, especialmente en el caso de individuos de Europa Occidental, mientras que el número de norteamericanos se ha mantenido relativamente constante. Sin embargo, el crecimiento más destacable es el de combatientes extranjeros de Rusia y Asia Central, ya que se estima que desde junio de 2014 la cifra ha aumentado en casi un $300 \%$. Por otro lado, se calcula que en torno un $20 \%$ y un $30 \%$ representa la tasa de repatriados a Occidente, lo cual supone una gran amenaza y un difícil reto para los cuerpos y fuerzas de seguridad. ${ }^{17}$ Sin embargo, en los últimos meses, según informa el Pentágono, la cifra de combatientes extranjeros ha ido en descenso, contabilizando una media de 200

\footnotetext{
${ }^{15}$ Organización para la Liberación de Palestina: "Movimiento nacionalista de Palestina y organización central de todos los movimientos palestinos" señala Napoleoni. Desde su nacimiento en 1964, tiene como objetivo "la creación de un estado palestino independiente en el territorio actualmente ocupado por Israel, o cuando menos en las zonas ocupadas por Gaza y Cisjordania"(Napoleoni, 2015, p. 126).

${ }^{16}$ Organización creada en 1987 como rama palestina de los Hermanos Musulmanes, cuya pretensión es constituir un Estado Islámico en Palestina reemplazando el de Israel (Napoleoni, 2015, p. 122).

$17 \mathrm{http}: / /$ soufangroup.com/wp-content/uploads/2015/12/TSG_ForeignFightersUpdate3.pdf
} 
individuos al mes. "Es una disminución drástica en comparación con hace aproximadamente un año cuando entre 1500 y 2000 combatientes extranjeros se unían al grupo en Irak y Siria cada mes" declaró el general de las Fuerzas aéreas de Estados Unidos, Peter Gersten ${ }^{18}$.

Por otro lado, Napoleoni advierte que el reclutamiento y la radicalización le resulta muy económico al grupo terrorista, puesto que se hace todo a través de Internet y las redes sociales, eliminando, además, cualquier barrera física. Por tanto, no es necesario viajar hasta Siria e Irak para radicalizarse y regresar para perpetrar atentados. La organización, a diferencia de Al Qaeda que seguía una estructura de mando piramidal y que estaba centralizada, sigue un modelo horizontal en el que da total libertad a cualquiera que desee unirse a sus filas para actuar por cuenta propia en nombre del califato. El rápido proceso de radicalización y reclutamiento supone también una gran preocupación para los gobiernos de todo el mundo, ya que se consuma en tan solo unas semanas, y se puede efectuar de manera autodidacta a través de los contenidos propagandísticos que difunde el Daesh (Napoleoni, 2015).

\section{CONCLUSIONES}

- El Daesh usa el periodismo como herramienta de propaganda para expandir sus ideas, conseguir simpatizantes y sembrar el terror a nivel mundial.

- El enorme poder financiero de la organización le permite crear productos propagandísticos de gran calidad.

- Los productos propagandísticos que transmite el grupo terrorista tienen gran difusión e impacto.

- La capacidad comunicativa del Daesh está muy desarrollada y es efectiva en su propósito de captación.

El terrorismo yihadista representa una amenaza a nivel global, haciendo a la sociedad consciente de la magnitud del fenómeno ante el que se enfrenta. Al igual que todos los avances que se han producido a lo largo de los años, este tipo de terrorismo también ha evolucionado adaptándose a la nueva coyuntura en la que las tecnologías de la información y la comunicación juegan un papel muy importante. El Daesh ha sabido cómo utilizar los avances tecnológicos del mundo occidental, adaptándolo a su mundo primitivo para sembrar el terror, crear su califato y captar seguidores.

- Se ha podido comprobar que el Daesh usa el periodismo como herramienta de propaganda, ya que cuenta con todo tipo de medios de comunicación para difundir su ideario, engrosar sus filas y sembrar el terror. Tiene un férreo control sobre los medios y las informaciones que circulan dentro de los territorios que tiene bajo su control para evitar que la población pueda tener otra perspectiva. Por tanto, por un lado, dentro de sus territorios la información ajena a la organización está censurada y, a su vez, inunda a sus habitantes de propaganda y, por otro lado, difunde su ideología al resto del

\footnotetext{
18 http://www.hispantv.com/noticias/ee-uu/253744/pentagono-combatientes-extranjeros-ei-siria-irak
} 
mundo a través de Internet y otros de sus medios de comunicación, como su revista Dabiq.

- El poder financiero que tiene le convierte en una de las organizaciones terroristas más ricas del mundo. En la actualidad, el Daesh goza de independencia económica y eso le hace aún más peligroso. Gracias a esta solvencia ha podido crear sus propios medios de comunicación, los cuales son bastante sofisticados y, además, crear productos propagandísticos de gran calidad.

- Los productos propagandísticos del Daesh tienen gran difusión e impacto porque la agrupación ha creado toda una estrategia de marketing alrededor de estos, adaptándose a los gustos de los más jóvenes, buscando el impacto, lo cual no deja indiferente a nadie en una sociedad en la que se demanda el morbo y las emociones fuertes. Además, cuenta con el canal de difusión por excelencia, Internet, a través del cual puede distribuir todos sus contenidos sin límites temporales, ni espaciales y favorecido por la inmediatez. Pero si algo hay que destacar en este sentido, son las redes sociales, a través de las cuales los contenidos se hacen virales en cuestión de minutos. $Y$ a pesar de la lucha de las fuerzas y cuerpos de seguridad para detener a la organización, los integrantes yihadistas son muy activos, por lo que el flujo de contenidos es constante.

- La capacidad comunicativa de la agrupación es, sin duda, impresionante. Los logros que ha conseguido en este sentido se han plasmado en el elevado número de individuos que ha captado para movilizarse hasta Siria e Irak. Este hecho ha despertado gran preocupación entre los expertos por el peligro que representa, no solo por aquellos que van a luchar junto al Daesh para extender su califato $\mathrm{y}$, que, en algunos casos, regresan adiestrados a Occidente para perpetrar atentados, sino, sobre todo, por un hecho mucho más complicado de controlar, la auto radicalización que se produce en Occidente a través de Internet y que se consuma en un periodo muy breve de tiempo. Este es otro de los peligros a los que la sociedad no se había enfrentado antes, un grupo terrorista que da carta blanca a todos aquellos que quieran luchar por su causa.

Desde que surgiese el Daesh y proclamase su califato en 2014, se ha podido comprobar su capacidad de actuación, destacando su aparato propagandístico.

\section{REFERENCIAS}

Alonso Mosquera, M. H., Gonzálvez Vallés, J. E. y Muñoz de Luna, A. B. (2016). Ventajas e inconvenientes del uso de dispositivos electrónicos en el aula: percepción de los estudiantes de grados en comunicación. Revista de Comunicación de la SEECI, XX(41), 136-154. doi: http://dx.doi.org/10.15198/seeci.2016.41

Alonso, R. (2015). El terrorismo yihadista: una amenaza híbrida. Cuadernos de pensamiento político, 61-80. FAES. Recuperado de https://fundacionfaes.org/file upload/publication/pdf/20150113172938el t errorismo yihadista- una amenaza hibrida.pdf 
Antena 3 (2016). Daesh lanza una campaña para prohibir las antenas parabólicas en Siria e Irak porque "siembran rumores". Recuperado de http://www.antena3.com/noticias/mundo/daesh-lanza-campana-prohibir- a n t e nas-parabolicas-siria-irak-porque-siembranrumores 20160601574f45694beb28110c2a31f6.html

Bakker, E. (2006). Jihadi terrorist in Europe, their characteristics and the circumstances in which they joined the jihad: an exploratory study. La Haya: Clingendael Institute.

Caretti, G. (2016). RTVE. Recuperado de http://www.rtve.es/noticias/20160805/propaganda- del-daesh-arma-mas-eficazdel-califato-terrorista/1381785.shtml

Cockburn, P. (2015). ISIS. El retorno de la yihad. Barcelona: Ariel.

Cockburn, P. (2014). The rise of Islamic state. Nueva York: Verso.

de Arístegui, G. (2004). El islamismo contra el islam. Las claves para entender el terrorismo yihadista. Barcelona: Sine qua non.

de Arístegui, G. (2005). La Yihad en España. Madrid: La esfera de los libros.

de la Corte Ibáñez, L., y Jordán, J. (2007). La Yihad terrorista. Madrid: Síntesis.

de la Corte Ibáñez, L. (2015). ¿Por qué se radicalizan los yihadistas europeos? Observatorio Internacional de Estudios sobre Terrorismo. Recuperado de http://observatorioterrorismo.com/sociologia/por-que-se-radicalizan-los-yihadistaseuropeos/

El Mundo (2016). Amaq, la agencia del ISIS. Recuperado de http://www.elmundo.es/television/2016/01/18/569a809b22601dca238b4667.html

Francheschi-Bicchierai, L. (2014). Russia's Facebook Cracks Down on ISIS Accounts, Mashable. Recuperado de https://mashable.com/2014/09/12/isis-islamic-statevkontakte-russia/?europe $=$ true \#klB6M9DmkPqX

García Ponce, D. y Smolak-Lozano, E. (2013). Comunicación de crisis: compilación y revisión de teorías y taxonomías prácticas desde una perspectiva cualitativa. Revista de Comunicación Vivat Academia Año XV124), 51-67. doi: http://dx.doi.org/10.15178/va.2013.124.51-67

Gambhir, H. (2014). Dabiq: the strategic messaging of the Islamic State. Institute of Study of War. Recuperado de http://understandingwar.org/sites/default/files/Dabiq\%20Backgrounder Harleen\% 20Final.pdf 
Poveda Criado, M. A. (2019). El periodismo como arma de captación terrorista

Garriga, David. (2016). Radiografía de los últimos yihadistas radicalizados. Observatorio Internacional de Estudios sobre Terrorismo. Recuperado de http://observatorioterrorismo.com/sociologia/radiografia-de-los-ultimosradicalizados/

Hispan TV (2016). Pentágono: menos combatientes extranjeros se unen al Daesh. Recuperado de http://www.hispantv.com/noticias/ee-uu/253744/pentagonocombatientes-extranjeros-ei-siria-irak

Howard, R.; Prohov, J., y Elliot, M. (2015). Digging in and Trafficking Out: How the Destruction of Cultural Heritage Fund Terrorism. CTC Sentinel, 8, pp.14-18.

Hoyakem, E. (2014). Iran, the Gulf States and the Syrian Civil War. Survival, 56(16), pp. 65.

Jordán Enamorado, J. (2015). El Daesh. Cuadernos de Estrategia: La internacional yihadista, 173, pp. 109-147. Recuperado de http://digibug.ugr.es/bitstream/10481/41175/1/Daesh-Estado-Islamico.pdf

Kimhi, Shaul \& Even, S. (2003). Who are the Palestinian suicide bombers? Terrorism and Political Violence, 16, 815-840.

Marta-Lazo, C., Grandío Pérez, M. M. y Gabelas Barroso, J.A. (2013). La educación mediática en las titulaciones de educación y comunicación de las Universidades españolas. Análisis de los recursos recomendados en las guías docentes. Revista de Comunicación Vivat Academia, XVII(126), 63-78. doi: http://dx.doi.org/10.15178/va.2014.126.63-78

Viñarás Abad, M. (2010). El discurso de la RSC en los medios de comunicación social. Revista de Comunicación Vivat Academia, XIII(11), 160-181. doi: http://dx.doi.org/10.15178/va.2010.110.160-181

\section{AUTOR:}

\section{Miguel Ángel Poveda Criado}

Doctor en periodismo por la Universidad Complutense de Madrid - UCM (2008). Doctor en paz y seguridad nacional por la Universidad Nacional de Educación a Distancia - UNED (2010,). Doctor en Ciencias Sociales y Políticas por la Universidad Técnica de Lisboa - UTL (2011) y licenciado en Comunicación Audiovisual (19841988) por la Universidad Complutense de Madrid. Máster en producción en cine y TV de bajo presupuesto en la Universidad de California, Los Ángeles (UCLA, 1991); máster en Protocolo (UNED, 2005); máster en Seguridad y Defensa (UNED, 2005); máster en Derecho Nobiliario, Premial, Herádica y Genealogía (UNED, 2003); máster en Protocolo y Relaciones Institucionales (IE, 2003) y diplomado en Protocolo y Relaciones Internacionales (EIP, 1998-1999).

Mapoveda1@yahoo.es

Orcid ID: https://orcid.org/0000-0002-5443-2197 